\title{
Update on thromboprophylaxis in orthopedic surgery and critical appraisal of the role of enoxaparin
}

\section{Jan Man Wong \\ Yoon Kong Loke}

Norwich Medical School, University of East Anglia, Norwich, United Kingdom

Correspondence: Yoon Kong Loke Norwich Medical School, University of East Anglia, Norwich, United Kingdom, NR4 7TJ

Tel +44 I603 59 I234

Fax +44 I603 593752

Email y.loke@uea.ac.uk
This article was published in the following Dove Press journal:

Orthopedic Research and Reviews

12 May 2012

Number of times this article has been viewed

\begin{abstract}
Orthopedic surgery is considered one of the most prominent risk factors for venous thromboembolism (VTE), but the optimal strategy for thromboprophylaxis remains a debatable topic. Consistent and reliable definitions of clinically relevant VTE and major bleeds in orthopedic research are particularly contentious areas, resulting in uncertainty about the actual benefit-harm balance of available interventions. For the newer oral anticoagulants, short-term clinical trials in highly selected patients with asymptomatic VTE (from mandatory radiological screening) must be supplemented by long-term efficacy and safety data in real-world settings (such as the Global Orthopedic Registry). The evidence gap leads to visible differences among recent recommendations from bodies such as the American College of Chest Physicians (2012), the American Academy of Orthopedic Surgeons (2011), and the National Institute of Clinical Excellence, England (NICE, 2012). While thromboprophylaxis after hip and knee arthroplasty is clearly recommended by all three bodies, there is no consistent agreement on the optimal agent or the duration of prophylaxis. Differences in opinion stem from subjective judgments on the relative weighting given to asymptomatic as opposed to symptomatic VTE, and the impact of major bleeding. While the newer oral anticoagulants (such as rivaroxaban and apixaban) seem to offer significant benefits compared to enoxaparin in the reduction of asymptomatic VTE, the data are limited by the paucity of symptomatic VTE and inconsistencies in capturing major bleeds. The lack of long-term experience in real world patients means that it is too early to judge whether the obvious convenience of newer oral anticoagulants will result in better patient adherence, safety, and quality of life as compared to enoxaparin. Further research should focus on clinically relevant outcomes, with clear definitions of bleeding, so that the benefit-harm trade-offs related to the diverse agents can be assessed through methods such as multiple treatment comparison meta-analysis.
\end{abstract}

Keywords: enoxaparin, low-molecular-weight heparin, orthopedic surgery, venous thromboembolism, thromboprophylaxis, Global Orthopedic Registry (GLORY)

\section{Background}

\section{Venous thromboembolism as a public health issue}

Venous thromboembolism (VTE) can present in a diverse number of ways, ranging from asymptomatic deep venous thrombosis (DVT) detected on radiographic screening, to life-threatening or fatal pulmonary embolism (PE). The incidence of VTE overall is approximately one to two cases per 1000 patients per year, ${ }^{1}$ with higher levels of risk reported in Caucasians, females, and those 80 years of age or older. ${ }^{2}$ VTE is thought to account for $10 \%$ of deaths in postmortem examination, which equates to an estimated 32,000 (United Kingdom) and 1.5 million (Europe) deaths 
per year. ${ }^{3,4}$ In the United States, 200,000 deaths a year stem from PE, a number that exceeds the total sum of deaths from acquired immune deficiency syndrome, breast cancer, and road traffic accidents. ${ }^{5}$ The annual cost of managing VTE is estimated to be $£ 640$ million in the UK and $€ 3.07$ billion in Europe..$^{3,4}$ Despite appropriate medical therapy, studies show that up to $50 \%$ of DVT patients can develop chronic persistent pain from postthrombotic syndrome, whereas pulmonary hypertension is a recognized complication that occurs in up to $5 \%$ of patients suffering from PE. ${ }^{6,7}$ The risk of mortality, long-term morbidity, and costs involved in managing VTE pose a considerable burden on the public health system.

\section{Risk of VTE in orthopedic surgery}

Virchow's triad has long been used to describe the pathology of thrombus formation in VTE, with the key driving factors arising from changes in vessel wall epithelium, blood flow, and constituents of the blood. Major surgical procedures put patients in a hypercoagulable state by altering hemodynamic stasis from immobility and mechanical vascular damage from the operative intervention. Orthopedic procedures such as hip fracture surgery (HFS), total hip replacement (THR), and total knee replacement (TKR) are thought to be particularly problematic owing to the physical and mechanical impact on the venous system of the lower limb. Independent risk factors for VTE, such as advanced age and obesity, are also increasingly prominent in patients undergoing major orthopedic procedures. ${ }^{8}$ Therefore, a combination of predisposing surgical and patient risk factors for VTE may result in a 50\% higher rate of DVT in orthopedic surgery if no prophylaxis is given. ${ }^{9}$ A consensus meeting of the American College of Chest Physicians (ACCP) considered lower-limb orthopedic operations to be of "highest risk" in the stratification of VTE risk according to patient susceptibility and the type of surgical procedure employed (see Table 1). ${ }^{10}$

However, interpretation of the rates of VTE in orthopedic surgery are clouded by the differences between study sites, time frame, methods of diagnosing VTE, and thromboprophylaxis protocols. A Japanese trial reported a total VTE rate of $>50 \%$ in the placebo arm (all patients underwent mandatory bilateral venography that would pick up asymptomatic DVTs), but the actual symptomatic DVT rate in this study was only $1.6 \% .{ }^{11}$ More recently, Januel et al presented a meta-analysis of symptomatic VTE rates prior to hospital discharge in hip and knee surgery patients who were treated with low-molecularweight heparin (LMWH), fondaparinux, or oral inhibitors of factors Xa or IIa. ${ }^{12}$ This meta-analysis examined 47 studies (42 trials and five observational studies) with 44,844 patients and found a prehospital discharge symptomatic VTE rate of $1.09 \%$ and $0.53 \%$ for TKR and THR, respectively. However, for a variety of methodological reasons, the truth likely lies somewhere between these two figures.

In the first instance, VTE may be under-diagnosed, as up to $75 \%$ of postmortem diagnoses are unsuspected prior to the death. ${ }^{10}$ Furthermore, the sensitivity and specificity of radiological investigations for VTE (such as Doppler ultrasonography) can vary depending on the user. Equally, patients undergoing major surgery to their lower limbs may have leg pain and swelling for a variety of other reasons, therefore, the nonspecific clinical features of VTE may be missed. In the absence of rigorous ascertainment and monitoring, it could be argued that the rates of VTE may be underestimated in certain studies.

From a scientific viewpoint, the most rigorous method of monitoring VTE is to implement mandatory radiological assessment to capture all patients. For instance, ultrasound scanning is generally accepted as a convenient and noninvasive screening tool for lower limb DVT. The use of blinded investigators and independent adjudication can reduce some of the imprecision stemming from subjectivity and variability between observers. Moreover, with mandatory screening, there is no need to rely on subjective clinical judgment in referring patients to hospitals for further investigation of suspected VTE. This is of particular importance given the possibility of under-ascertainment in clinical set-

Table I Risk of VTE in surgical patients without prophylaxis ${ }^{10}$

\begin{tabular}{|c|c|}
\hline Estimated degree of risk for proximal DVT or PE & Patient characteristics and risk factors for VTE \\
\hline $0.2 \%-0.4 \%$ & Age $<40$ years, with no apparent VTE risk factors undergoing minor procedures. \\
\hline Up to $4 \%$ & $\begin{array}{l}\text { Surgical procedures in those aged } 40-60 \text { years, or minor operations in those } \\
\text { with VTE risk factors. }\end{array}$ \\
\hline Up to $8 \%$ & $\begin{array}{l}\text { Surgical procedures in older patients age }>60 \text { years, or younger patients } \\
\text { aged } 40-60 \text { years with VTE risk factors. }\end{array}$ \\
\hline Up to $20 \%$ & $\begin{array}{l}\text { Patients age }>40 \text { years with risk factors such as a past history of VTE, or patients } \\
\text { undergoing hip surgery/knee replacement. }\end{array}$ \\
\hline
\end{tabular}

Abbreviations: DVT, deep vein thrombosis; PE, pulmonary embolism; VTE, venous thromboembolism. 
tings due to nonspecific or out-of-hospital presentations of VTE. Nevertheless, the high internal validity of radiological screening is offset by the perceived loss of applicability or generalizability of such data to real-life clinical practice. Many believe that the DVTs detected with mandatory screening in clinical trials are of uncertain relevance, while symptomatic DVT/PEs are still thought to be the most meaningful measure.

Mandatory radiological screening for VTE can be problematic in clinical trials after patients have undergone orthopedic surgery because high rates of asymptomatic DVT may be detected, many which may be of no clinical relevance. However, because such inpatient screening can lead to a substantial proportion of asymptomatic DVT patients receiving early treatment with warfarin or other vitamin $\mathrm{K}$ antagonists (VKAs), the rates of symptomatic VTE may be very low thereafter. This may partially explain why recent trials of newer anticoagulants are unable to demonstrate differences in symptomatic DVT or PE rates between different treatment arms. Equally, it has been argued that the rates of symptomatic VTE in Januel's recent meta-analysis are underestimated because of the mandatory screening involved, relatively short follow-up periods, and the lack of generalizability to real-world patients. ${ }^{13}$ In view of the inconsistencies and limitations of the current dataset, as well as the rapidly changing face of clinical practice stemming from the profusion of new oral pharmacological agents, it is clear that additional real-world studies of VTE in orthopedic surgery are required. The next section provides examples of two current initiatives involving registry-based data.

\section{New information}

\section{The Global Orthopedic Registry}

In 2002, the Global Orthopedic Registry (GLORY) was constructed following the merger of two existing registries: the International Orthopedic Registry (IOR) and the North American Hip and Knee Registry (THKR). GLORY is now a multinational, multicentre, observational study that aims to "gather and analyze real-life data on THR/TKR patients with respect to treatment practices and patient outcomes, including assessment of rapidly evolving clinical practice guidelines for the prevention of VTE."14 Data is collected from Australia, Brazil, Canada, France, Germany, Italy, Japan, Spain, the UK, and the USA with the projected enrollment of at least 5000 patients every year to generate a large sample size for benchmarking treatment patterns and patient outcomes. The most recent publication from GLORY reported that some form of VTE prophylaxis was used in $99.0 \%$ of TKR and THR procedures. ${ }^{15}$ However, full compliance with ACCP guidelines was found in only $62 \%$ and $69 \%$ of patients undergoing THR and TKR, respectively, with a significantly lower rate in the USA. ${ }^{16}$ The report also shows that LMWHs are the favored method of VTE prophylaxis. ${ }^{16}$

The strength of GLORY lies in its collection of worldwide data that more closely reflects real-world practice, which increases its clinical relevance and applicability. While the observational nature of GLORY may preclude robust comparisons between different pharmacological regimens, the data may be used to identify initial signals or alerts such as any significant differences in patient outcomes between healthcare systems. The Quarterly Report by GLORY includes demographics, preoperative and perioperative data, use of VTE prophylaxis, complications, and quality of life assessments. All of these data can help to facilitate timely recognition and intervention for any areas that should be targeted for quality improvement programs. ${ }^{14}$

However, an important limitation of GLORY is that most of the participating sites are large academic centers. However, existing efforts to recruit more nonacademic and communitybased hospitals should help to improve the generalizability of the data. ${ }^{14}$ Moreover, as "surgery for traumatic fractures" is currently excluded from the registry, the data lacks relevance for units that take on the ever-increasing burden of patients with a fractured neck or femur.

Apart from GLORY, it is worth noting that efforts are being made to capture real-world outcomes with the newer oral anticoagulants, outside of highly selected trial participants who may have a low risk of adverse effects. For instance, concerns remain among orthopedic surgeons about any potential increase in wound hemorrhaging and infection rates with rivaroxaban. ${ }^{17}$ In order to address this, Bayer initiated a prospective cohort study in 2009 (Clinical Trials Identifier: NCT00831714) ${ }^{18}$ with the aim of collecting safety data from 15,000 patients undergoing THR or TKR who had received either rivaroxaban or "standard care." The cohort involves participants from 42 countries, with outcomes of interest including "bleeding events that are reported as serious or non-serious adverse events, symptomatic VTE as adverse events, uncommon adverse events (defined as incidence rate $0.1 \%-1 \%$ ), and all cause mortality." The anticipated completion date of the primary data collection was June 2011. Both of these large registry studies will provide useful real-world epidemiological data on the use of VTE prophylaxis, rates of VTE, and complications related to treatment (either as a result of surgery or the use of pharmacological agents). 


\section{Current guidelines on thromboprophylaxis for orthopedic surgery}

Owing to the diverse range of available interventions and the recent emergence of several new therapeutic options, clinicians and patients are confronted by a complex dilemma in deciding which method of VTE prophylaxis is most suitable. Thromboprophylaxis can take the form of mechanical, pharmacologic, and/or ancillary means. Mechanical methods include antiembolism stockings, foot impulse devices, and intermittent pneumatic compression devices (IPC). Depending on the patient, pharmacological VTE prophylaxis can be applied using LMWH, unfractionated heparin (UFH), and other anticoagulants (such as VKAs, apixaban, dabigatran, fondaparinux, and rivaroxaban). Ancillary methods include early mobilization and prevention of dehydration.

This overwhelming array of options means that clinicians may have to seek advice from evidence-based guidelines produced by prominent professional bodies. The most recent guides are those issued by the ACCP in February 2012, ${ }^{19}$ NICE in 2010 and January 2012,,$^{20,21}$ and the American Association of Orthopedic Surgeons (AAOS) in September 2011. ${ }^{22}$ Table 2 summarizes and compares the key recommendations from these guidelines. As there are several key areas where the professional bodies have reached differing conclusions, an in-depth examination of certain specific aspects may help to explain potential reasons for divergence in opinion.

The ninth update of the ACCP guidelines in February 2012 recommends pharmacological thromboprophylaxis with an IPC device for THR or TKR, with LMWH being preferred as the first-line option over other pharmacological agents. ${ }^{19}$ Unlike previous ACCP guidelines, this update was led mainly by methodologists rather than specialists in orthopedic surgery and/or thrombosis, in order to reduce the potential for financial and intellectual conflicts of interests. The main focus of the ACCP consensus was modelling the absolute number of symptomatic VTE events prevented, as opposed to the major bleeds resulting from pharmacological prophylaxis.

Although the ACCP panel accepted that a variety of agents such as VKAs, aspirin, fondaparinux, dabigatran, rivaroxaban, and apixaban were efficacious and suitable for use, the guidelines argued that LMWH had the best balance between benefits and harms, particularly with regards to the long-term track record. Aspirin was a particularly contentious recommendation as the ACCP analysis found that aspirin therapy was associated with a statistically significant higher risk of DVT when compared to LMWH. However, concomitant use of aspirin and a pneumatic compression device was found to yield favorable results for DVT and major bleeding events. Table 2 summarizes the quantitative analysis and benefit-harm modelling described by the ACCP, which will be further discussed in a later section considering the risk-benefit profile of LMWH.

The NICE guidelines emphasize mechanical intervention at admission prior to the surgery as well as pharmacological prophylaxis after THR (for 28-35 days) and TKR (for 10-14 days). ${ }^{20}$ In contrast to the ACCP guidelines, NICE supported fondaparinux, apixaban, rivaroxaban, and dabigatran as favorable alternatives to LMWH in their modelling of cost-effectiveness. The most recent technology appraisal from NICE in January 2012 estimated that both apixaban and rivaroxaban could potentially be considered dominant in an economic model compared to enoxaparin, although the absolute differences in cost-effectiveness were generally minor. ${ }^{21}$

Although the most recent AAOS guidelines supported the use of pharmacological and mechanical prophylaxis after

Table 2 Summary of recent guidelines on the prevention of VTE in patients undergoing orthopedic surgery

\begin{tabular}{|c|c|c|c|}
\hline & AAOS $(2011)^{22}$ & $\operatorname{ACCP}(2012)^{19}$ & NICE $(2010 \text { and } 2012)^{20,21}$ \\
\hline \multicolumn{4}{|c|}{ Elective hip or knee arthroplasty } \\
\hline $\begin{array}{l}\text { - No other risk } \\
\text { factor } \\
\text { - With previous VTE } \\
\text { - With known } \\
\text { bleeding disorder } \\
\text { and/or active } \\
\text { liver disease }\end{array}$ & $\begin{array}{l}\text { Pharmacological agents } \\
\text { and/or mechanical device } \\
\text { Pharmacological agents } \\
\text { and mechanical } \\
\text { compressive devices } \\
\text { Mechanical compressive } \\
\text { devices }\end{array}$ & $\begin{array}{l}\text { - LMWH (in preference to alternatives) } \\
\text { irrespective of compressive device use. } \\
\text { Start either } 12 \text { hours preoperation or } \\
12 \text { hours post operation. Continue for } \\
\text { only } 3 \text { days rather than 10-14 days. } \\
\text { Mechanical device (or no prophylaxis) } \\
\text { for those with bleeding risk } \\
\text { - Oral agents reserved for patients } \\
\text { uncooperative with injections or } \\
\text { compressive devices }\end{array}$ & $\begin{array}{l}\text { - At admission: any mechanical prophylaxis } \\
\text { (antiembolism stockings, foot impulse device, } \\
\text { compressive devices) } \\
\text { - Start pharmacological prophylaxis I-12 hours } \\
\text { after surgery; recommended duration } 28-35 \text { days } \\
\text { for THR and I0-14 days for TKR }\end{array}$ \\
\hline
\end{tabular}

Abbreviations: AAOS, American Association of Orthopedic Surgeons; ACCP, American College of Chest Physicians; LMWH, low-molecular-weight heparin; NICE, National Institute of Clinical Excellence, England; THR, total hip replacement; TKR, total knee replacement; UFH, unfractionated heparin; VTE, venous thromboembolism. 
TKR and THR, the panel was unable to recommend for or against any specific strategy or drug. ${ }^{22}$ The AAOS claimed that the data were based mainly on DVT rather than the more clinically important measure of PE, and as such, there was insufficient evidence to judge if any particular interventional strategy was clinically superior. Equally, the AAOS stated that there was little reliable evidence on the optimal duration of thromboprophylaxis, and recommended that this decision be left to physicians and patients.

The apparent differences between these recent guidelines may stem from variation in the selection of studies, different grading of evidence, and subjective value judgments of the relative importance of asymptomatic or symptomatic VTE against hemorrhagic events. Equally, one noticeable difference between the US and UK data was that enoxaparin is conventionally prescribed as $30 \mathrm{mg}$ twice daily in the US, while it is $40 \mathrm{mg}$ once daily in Europe (the main dose considered by NICE), which results in divergent findings in trials that depend on the enoxaparin regimen. Nevertheless, all the guidelines concur in their recommendations of mechanical and pharmacological prophylaxis, even though the relative merits and disadvantages of each pharmacological agent may need to be judged according to the preferences of the individual patient and physician.

\section{Adherence to guidelines}

Despite the best intentions of the guidelines' authors, adherence to guidelines can vary considerably by country and clinical practice. A systematic review demonstrated that passive dissemination of guidelines was unlikely to improve uptake of VTE prophylaxis. Instead, the most effective strategies seemed to be those that incorporated a reminder or alert system for clinicians to assess VTE risk in patients, followed by subsequent audit feedback. ${ }^{23} \mathrm{~A}$ cross-sectional study that included patients from 32 countries showed that only $58.5 \%$ of surgical patients with risk factors were given the appropriate VTE prophylaxis as per ACCP protocol, and even less (39.5\%) for medical patients. ${ }^{24}$ Another analysis reported a high rate of compliance (up to $84 \%$ ) together with $37 \%$ preventable VTE, of which 20 deaths occurred amongst 37,615 patients. ${ }^{25}$ It has become apparent that more stringent compliance with VTE guidelines and continual monitoring through auditing is of paramount importance for reducing serious VTE-related events.

\section{Therapeutic activity of LMWH}

LMWH works by activating antithrombin III and preferentially potentiate inhibition of factors Xa and IIa (see Figure 1). As a result, there is decreased thrombin formation and less likelihood of fibrin clot formation. There are many examples of LMWHs (eg, enoxaparin, dalteparin, and tinzaparin), but LMWH typically has a smaller molecular size and better bioavailability through the subcutaneous route than UFH. ${ }^{26}$ Although "LMWH" is a widely used term, much of the following discussion surrounding LMWH in orthopedic surgery is most pertinent to enoxaparin.

Enoxaparin is one of the most popular forms of pharmacological VTE prophylaxis in the GLORY dataset, ${ }^{16}$ and

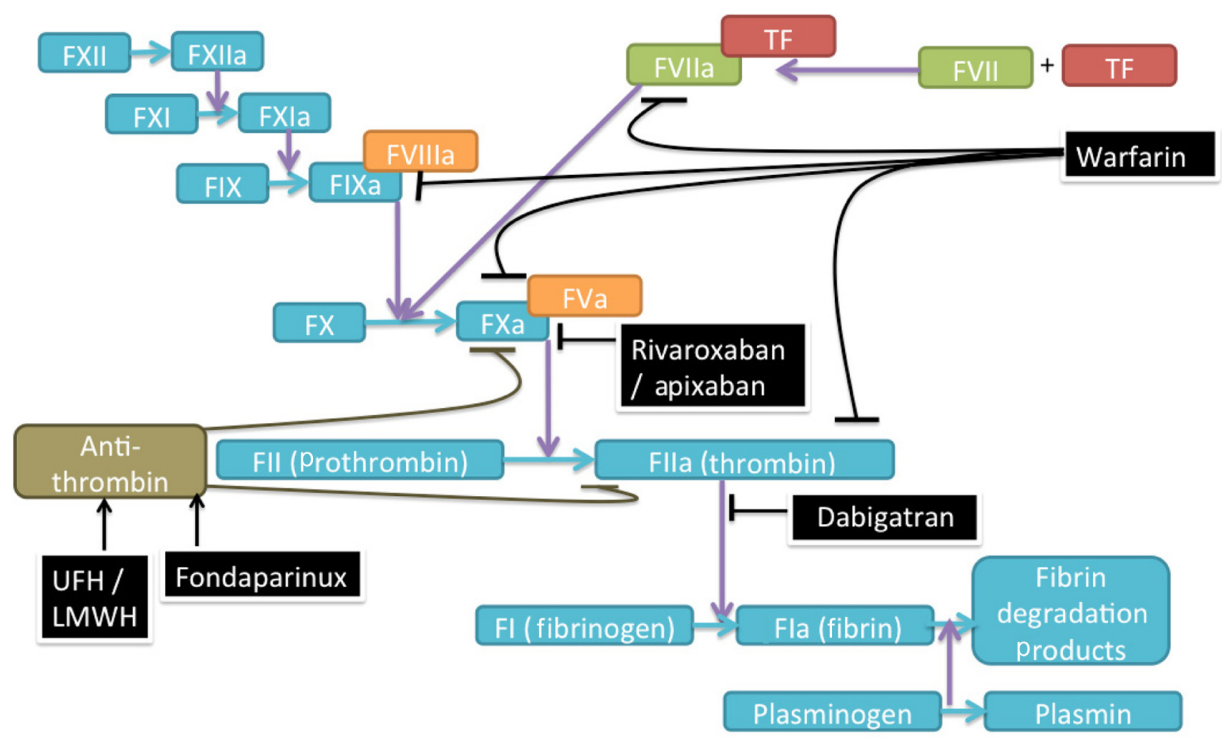

Figure I Mechanism of actions of pharmacological VTE prophylaxis.

Note: Pointed arrows indicate potentiation or stimulation; blunt-headed arrows indicate inhibition.

Abbreviations: F, factor; TF, tissue factor; UFH, unfractionated heparin; LMWH, low-molecular-weight heparin. 
a substantial proportion of the LMWH clinical trial data in hip and knee surgery is based on comparisons of enoxaparin against placebo or other active agents. This is particularly true with regards to recent trials of new oral anticoagulants such as dabigatran or rivaroxaban in hip and knee surgery, where the comparator arm has almost always involved enoxaparin. ${ }^{27}$ It is worth noting that enoxaparin is also widely used for VTE prophylaxis in medical inpatients, where it is shown to have a beneficial number needed to treat (NNT) for the prevention of VTE and mortality of 471 and 78 , respectively. ${ }^{28}$

\section{LMWH in THR compared to VKAs or injectable agents} Meta-analyses have shown that LMWH has a superior effect in prophylaxis compared to UFH, with a relative risk reduction of $13.4 \%(P=0.0004)$ in total DVT in THR. ${ }^{29}$ LMWHs also showed a significant 50\% $(P<0.001)$ relative risk reduction in total DVT, but an increased risk of hemorrhaging, especially from days two to eight $(2.2 \%$ in preoperative dalteparin compared with $0.4 \%$ in warfarin, $P=0.1$ ), against Vitamin $\mathrm{K}$ antagonists such as warfarin. ${ }^{30}$ In contrast, fondaparinux, an indirect factor Xa inhibitor, significantly reduced the incidence of VTE in a study against enoxaparin $40 \mathrm{mg}$ od (RR 0.44, 95\% CI: 0.27-0.67) but not in another study against enoxaparin $30 \mathrm{mg}$ bd (RR 0.74, 95\% CI: 0.47-1.11) when compared with enoxaparin $40 \mathrm{mg} .{ }^{31}$

\section{LMWH in TKR compared to VKAs or injectable agents}

UFH is not recommended in TKR. Pooled data and metaanalyses show the superior effect of LMWH when compared to warfarin or heparin in TKR (RR 0.73, 95\% CI: $0.66-0.80) .{ }^{32}$ When compared with enoxaparin $30 \mathrm{mg}$ twice daily, fondaparinux reduced the risk of VTE (RR 0.45, 95\% CI: 0.30 RR 0.64, $P<0.001$ ), but was associated with a significantly increased major bleeding rate. ${ }^{33}$

\section{New oral anticoagulants compared to enoxaparin}

There are three new oral agents (dabigatran, rivaroxaban, and apixaban) that may potentially affect the use of enoxaparin in the future. Dabigatran is a direct thrombin inhibitor for factor IIa, whereas apixaban and rivaroxaban are both direct factor $\mathrm{Xa}$ inhibitors. The pooled data showed that rivaroxaban significantly reduces VTE risk compared to enoxaparin (pooled RR 0.56, 95\% CI: 0.43-0.73, $P<0.0001$ ), but also demonstrated the potential increased risk of hemorrhaging (pooled RR 1.26, 95\% CI: $0.94-1.69, P=0.13) .{ }^{27}$ Dabigatran showed no significant advantage over enoxaparin in VTE reduction (pooled RR 1.12, 95\% CI: 0.97-1.29, $P=0.12$ ) and hemorrhaging (pooled RR 1.10, 95\% CI: $0.90-1.35, P=0.34) .{ }^{27}$
There is mixed evidence over apixaban, depending on the comparator regimen used. In TKR, a double-blind randomized placebo-controlled trial (ADVANCE-1) did not show a significant advantage of apixaban for VTE compared to $30 \mathrm{mg}$ enoxaparin twice daily (RR 1.02, 95\% CI: 0.78-1.32, $P=0.06) .{ }^{34}$ However, a significant advantage in VTE prevention was demonstrated (RR 0.62 , 95\% CI: $0.51-0.74$, $P<0.0001)$ when apixaban was compared with the $40 \mathrm{mg}$ enoxaparin once-daily dose in the ADVANCE-2 trial. ${ }^{35}$ In THR, a randomized, controlled study showed a statistically significant reduction of all cause VTE and deaths (RR 0.36, 95\% CI: $0.22-0.54, P<0.001)$ without conclusive data on hemorrhaging. ${ }^{35}$

\section{Absolute benefit-harm balance of other interventions compared to LMWH}

It must be emphasized that the choice of VTE prophylaxis depends not only on the relative effects of VTE outcomes, but also on the balance-of-harm from hemorrhagic adverse events. Here, the ACCP argues that the most clinically relevant approach is to construct a model that compares the absolute rates of symptomatic VTE events against major hemorrhaging. ${ }^{19}$ Table 3 summarizes the key estimates of symptomatic DVT and major bleeds from the ACCP benefitharm model in hip replacement surgery to illustrate the potential impact of using different pharmacological agents as compared to enoxaparin. The ideal alternative to LMWH would offer significantly fewer DVTs and major bleeds, but none of the available options would meet this aim, other than possibly the combination of aspirin and a pneumatic compression device (for which the grade of evidence is currently low due to limited data). Table 3 demonstrates that there are pros and cons associated with all of the other options, and clinicians and patients will have to make their own value judgments when considering alternatives to LMWH.

\section{Quality of life and the convenience of VTE prophylaxis}

We were unable to identify any substantive published work demonstrating the improved quality of life and medication adherence from outpatient use of newer oral agents that do not require blood monitoring. Although oral medication can potentially increase patient adherence due to its convenience, a retrospective cohort study showed that, in the real-world outpatient setting, there is increased odds of VTE at 90 days for those receiving oral VKAs (OR 1.18, 95\% CI: 1.03-1.36, $P=0.02$ ) compared to injectable agents (including dalteparin, enoxaparin, and fondaparinux). ${ }^{36}$ This study was based principally on patients using warfarin, and the diminution in benefit 
Table 3 Absolute benefit or harm if other prophylactic strategies were used instead of LMWH in THR, based on ACCP model ${ }^{19}$

\begin{tabular}{|c|c|c|}
\hline \multirow[t]{2}{*}{$\begin{array}{l}\text { Alternative agent used } \\
\text { instead of LMWH }\end{array}$} & \multicolumn{2}{|c|}{$\begin{array}{l}\text { Anticipated change in absolute effects }(95 \% \mathrm{Cl}) \text { in contemporary } \\
\text { population per } 1000 \text { treated with alternative rather than LMWH }\end{array}$} \\
\hline & Symptomatic DVTs & Major bleeding events \\
\hline IPCD or FID & $\begin{array}{l}3 \text { more per } 1000 \\
\text { (from I fewer to } 8 \text { more) }\end{array}$ & $\begin{array}{l}10 \text { more per } 1000 \\
\text { (from } 2 \text { fewer to } 13 \text { fewer) }\end{array}$ \\
\hline $\begin{array}{l}\text { VKA } \\
\text { (initial prophylaxis) }\end{array}$ & $\begin{array}{l}2 \text { more per } 1000 \\
\text { (from I more to } 2 \text { more) }\end{array}$ & $\begin{array}{l}4 \text { more per } 1000 \\
\text { (from II fewer to I more) }\end{array}$ \\
\hline UFH (initial prophylaxis) & $\begin{array}{l}2 \text { more per } 1000 \\
\text { (from } 2 \text { more to } 3 \text { more) }\end{array}$ & $\begin{array}{l}\text { I more per } 1000 \\
\text { (from I fewer to } 4 \text { more) }\end{array}$ \\
\hline ASA (extended prophylaxis) & $\begin{array}{l}\text { II more per } 1000 \\
\text { (from } 2 \text { more to } 14 \text { more) }\end{array}$ & N/A \\
\hline IPCD and ASA & $\begin{array}{l}4 \text { fewer per } 1000 \\
\text { (from I fewer to } 6 \text { fewer) }\end{array}$ & $\begin{array}{l}\text { I } 4 \text { fewer per } 1000 \\
\text { (from } 4 \text { fewer to I fewer) }\end{array}$ \\
\hline Fondaparinux & $\begin{array}{l}2 \text { more per } 1000 \\
\text { (from } 4 \text { fewer to } 22 \text { more) }\end{array}$ & $\begin{array}{l}5 \text { more per } 1000 \\
\text { (from } 2 \text { fewer to } 16 \text { more) }\end{array}$ \\
\hline Dabigatran I50 mg (extended prophylaxis) & $\begin{array}{l}6 \text { more per } 1000 \\
\text { (from } 7 \text { fewer to } 51 \text { more) }\end{array}$ & $\begin{array}{l}4 \text { fewer per } 1000 \\
\text { (from } 9 \text { fewer to } 3 \text { more) }\end{array}$ \\
\hline Dabigatran 220 mg (extended prophylaxis) & $\begin{array}{l}4 \text { fewer per } 1000 \\
\text { (from II fewer to } 36 \text { more) }\end{array}$ & $\begin{array}{l}\text { I more per } 1000 \\
\text { (from } 5 \text { fewer to II more) }\end{array}$ \\
\hline Rivaroxaban (extended prophylaxis) & $\begin{array}{l}7 \text { fewer per } 1000 \\
\text { (from } 2 \text { fewer to } 10 \text { fewer) }\end{array}$ & $\begin{array}{l}9 \text { more per } 1000 \\
\text { (from } 2 \text { fewer to } 30 \text { more) }\end{array}$ \\
\hline Apixaban (extended prophylaxis) & $\begin{array}{l}7 \text { fewer per } 1000 \\
\text { (from I fewer to } 10 \text { fewer) }\end{array}$ & $\begin{array}{l}4 \text { fewer per } 1000 \\
\text { (from } 8 \text { fewer to } 5 \text { more) }\end{array}$ \\
\hline
\end{tabular}

Note: Statistically significant effects are denoted in bold.

Abbreviations: ACCP, American College of Chest Physicians; ASA, acetylsalicylic acid (aspirin); DVT, deep vein thrombosis; FID, foot impulse devices; GCS, graduated compression stockings; IPCD, intermittent pneumatic compression device; LMWH, low-molecular-weight heparin; THR, total hip surgery; UFH, unfractionated heparin; VKA, vitamin $\mathrm{K}$ antagonist.

may possibly be due to poorer international normalised ratio (INR) control. Nevertheless, medication adherence is a complex process, and it is possible that some patients may adhere more to injectable formulations than to the multitude of tablets they might already be taking, particularly where there may be extended nursing support required to ensure delivery of regular injections. The data for real-world adherence to the newer oral agents has not been reported; therefore, the presumed quality of life and convenience benefits of these new agents cannot be guaranteed.

\section{Conclusion}

This paper began by outlining the basic scientific principles of venous thromboprophylaxis, which essentially involves striking a fine balance between bleeding and thrombosis. For the newer anticoagulants, any increase in therapeutic efficacy may potentially be accompanied by an increased bleeding risk. As a result of this, some of the agents that seem promising in clinical trials may require longer-term experience before they can be recommended without reservation. The lack of consistency in defining and reporting "bleeding," or the exclusion of surgical-site hemorrhaging in some recent trials creates difficulties when interpreting the true benefit-harm balance. ${ }^{37}$ Given that surgical-site hemorrhaging can lead to wound complications such as dehiscence and infection, we suggest rigorous ascertainment of other adverse events (including wound infection and subsequent surgical revisions) to allow more thorough comparisons of long-term safety between the newer and older agents.

There are two important aspects of the benefit-harm trade-off that require further evaluation. One key area relates to resource utilization within the healthcare economy, which involves not only a cost-benefit analysis of the intervention, but also an analysis of the expenditures required to manage major bleeding events. There is also a need to clarify patient preferences with regards to convenience of oral agents that do not need monitoring, and subsequent adherence to therapy following discharge from the hospital, given that the need for INR monitoring with VKAs may positively influence greater compliance with therapy.

Therefore, we recommend that further research be conducted before drawing any firm conclusions that newer oral anticoagulants are superior to LMWHs such as enoxaparin. These should include trials with patient-centered outcome assessments involving:

- standardization of bleeding events, which will generate a comparable dataset for comparison; and 
- a sufficient sample size by which to detect differences in symptomatic VTE events (DVT and PE) at outpatient follow-up, instead of relying solely on the detection of asymptomatic inpatient DVT through mandatory screening.

In view of the continuing uncertainty surrounding choice of appropriate outcomes, we also propose an international initiative to reach a consensus or unified approach on the most clinically relevant outcome measures for VTE. The current debate over VTE has strong parallels with the previous uncertainty surrounding outcome measures in rheumatological research, which was subsequently addressed by the OMERACT (Outcome Measures in Rheumatology Clinical Trials) initiative. ${ }^{38}$ The eight biennial OMERACT conferences since 1992 have reached agreement on the outcome measures for four rheumatological conditions, as well as psychosocial and cost-effectiveness evaluations. The OMERACT experience has demonstrated the importance of patient opinion in defining "minimal clinically important differences" that are used to guide the design and conduct of clinical trials. We believe that this unified approach will be very useful for developing consensus among the numerous stakeholders, including orthopedic surgeons, radiologists, chest physicians, hematologists, and patients. Finally, the use of standardized measures for analyzing clinically relevant benefit and harm will allow a diverse selection of interventions to be assessed and compared through methods such as multiple-treatment comparison or network meta-analysis.

\section{Disclosure}

The authors report no conflicts of interest in this work.

\section{References}

1. Cohen AT, Dobromirski M, Lin SL, Wills JO. Venous Thromboembolism: The Magnitude of the Problem in Europe and the World. Adv Venous Arterial Thromb. 2011;1(2):39-45.

2. Beckman MG, Hooper WC, Critchley SE, Ortel TL. Venous thromboembolism: a public health concern. Am J Prev Med. 2010; 38(Suppl 4):S495-S501.

3. House of Commons UK. Select Committee on Health, Second Report. Available from: http://www.publications.parliament.uk/pa/cm200405/ cmselect/cmhealth/99/9906.htm\#n24. Accessed January 30, 2012.

4. Cohen AT, Agnelli G, Anderson FA, et al. Venous thromboembolism (VTE) in Europe. The number of VTE events and associated morbidity and mortality. Thromb Haemost. 2007;98(4):756-764.

5. American Public Health Association. Deep-Vein Thrombosis: Advancing Awareness to Protect Patient Lives (White Paper); 2003. Available from: http://www.apha.org/NR/rdonlyres/A209F84A-7C0E4761-9ECF-61D22E1E11F7/0/DVT_White_Paper.pdf. Accessed January 30, 2012.

6. Kahn SR, Ginsberg JS. Relationship between deep venous thrombosis and the postthrombotic syndrome. Arch Intern Med. 2004;164(1): $17-26$.
7. Kearon C. Natural history of venous thromboembolism. Circulation. 2003;107(23 Suppl 1):I22-I30.

8. Centre for Workforce Intelligence UK. Medical Specialty Workforce Factsheet - Trauma and Orthopedic Surgery; 2011. Available from: http://www.cfwi.org.uk/intelligence/cfwi-medical-factsheets/ recommendation-for-trauma-and-orthopedic-surgery-training-2011. Accessed January 30, 2012.

9. Nicolaides AN, Fareed J, Kakkar AK, et al. Prevention of venous thromboembolism. International Consensus Statement. Guidelines compiled in accordance with the scientific evidence. Int Angiol. 2006;25(2): 101-161.

10. Geerts WH, Pineo GF, Heit JA, et al. Prevention of venous thromboembolism: the Seventh ACCP Conference on Antithrombotic and Thrombolytic Therapy. Chest. 2004;126(Suppl 3):400.

11. Fuji T, Fuijita S, Ujihira T, Sato T. Dabigatran etexilate prevents venous thromboembolism after total knee arthroplasty in Japanese patients with a safety profile comparable to placebo. J Arthroplasty. 2010;25(8): 1267-1274.

12. Januel JM, Chen G, Ruffieux C, et al. Symptomatic in-hospital deep vein thrombosis and pulmonary embolism following hip and knee arthroplasty among patients receiving recommended prophylaxis: a systematic review. JAMA. 2012;307(22253396):294-303.

13. Heit JA. Estimating the incidence of symptomatic postoperative venous thromboembolism: the importance of perspective. JAMA. 2012; 307(22253398):306-307.

14. Global Orthopedic Registry. GLORY - Assessing Today's Practice Patterns to Enhance Tomorrow's Care; 2002. Available from: http:// www.outcomes-umassmed.org/GLORY/Files/GLORYBrochure.pdf. Accessed January 30, 2012.

15. Waddell J, Johnson K, Hein W, Raabe J, FitzGerald G, Turibio F. Orthopedic practice in total hip arthroplasty and total knee arthroplasty: results from the Global Orthopedic Registry (GLORY). Am J Orthop. 2010;39(Suppl 9):5-13.

16. Friedman RJ, Gallus A, Gil-Garay E, FitzGerald G, Cushner F. Practice patterns in the use of venous thromboembolism prophylaxis after total joint arthroplasty - insights from the Multinational Global Orthopedic Registry (GLORY). Am J Orthop. 2010;39(Suppl 9):14-21.

17. Jensen CD, Steval A, Partington PF, Reed MR, Muller SD. Return to theatre following total hip and knee replacement, before and after the introduction of rivaroxaban: a retrospective cohort study. J Bone Joint Surg Br. 2011;93(1):91-95.

18. Clinical Trials Register. Xarelto for VTE Prophylaxis After Hip or Knee Arthroplasty (XAMOS). Available from: http://clinicaltrials.gov/ct2/ show/study/NCT00831714\#locn. Accessed February 8, 2012.

19. Falck-Ytter Y, Francis CW, Johanson NA, et al. Prevention of VTE in Orthopedic Surgery Patients: Antithrombotic Therapy and Prevention of Thrombosis, 9th ed: American College of Chest Physicians Evidence-Based Clinical Practice Guidelines. Chest. 2012; 141(Suppl 2):e278S-e325S.

20. National Institute for Health and Clinical Excellence E. Venous thromboembolism: reducing the risk, clinical guideline 92; 2010. Available from: http://guidance.nice.org.uk/CG92/NICEGuidance/pdf/English. Accessed January 30, 2012.

21. National Institute for Health and Clinical Excellence E. Venous thromboembolism - apixaban (hip and knee surgery) (TA245); 2012. Available from: http://guidance.nice.org.uk/TA245. Accessed February 25, 2012.

22. American Academy of Orthopedic Surgeons Clinical Practice Guidelines Unit. Guideline on Preventing Venous Thromboembolic Disease in Patients Undergoing Elective Hip and Knee Arthroplasty (Sept 2011). Accessed January 30, 2012.

23. Tooher R, Middleton P, Pham C, et al. A systematic review of strategies to improve prophylaxis for venous thromboembolism in hospitals. Ann Surg. 2005;241(3):397-415.

24. Cohen AT, Tapson VF, Bergmann JF, et al. Venous thromboembolism risk and prophylaxis in the acute hospital care setting (ENDORSE study): a multinational cross-sectional study. Lancet. 2008;371(9610):387-394. 
25. Shackford SR, Rogers FB, Terrien CM, Bouchard P, Ratliff J, Zubis R. A 10-year analysis of venous thromboembolism on the surgical service: the effect of practice guidelines for prophylaxis. Surgery. 2008;144(1): 3-11.

26. Knox C, Law V, Jewison T, et al. DrugBank 3.0: a comprehensive resource for 'omics' research on drugs. Nucleic Acids Res. 2011; 39(Database issue):8.

27. Loke YK, Kwok CS. Dabigatran and rivaroxaban for prevention of venous thromboembolism - systematic review and adjusted indirect comparison. J Clin Pharm Ther. 2011;36(1):111-124.

28. Montero Ruiz E, Baldominos Utrilla G, Lopez Alvarez J, Santolaya Perrin R. Effectiveness and safety of thromboprophylaxis with enoxaparin in medical inpatients. Thromb Res. 2011;128(5):440-445.

29. Freedman KB, Brookenthal KR, Fitzgerald RH Jr, Williams S, Lonner JH. A meta-analysis of thromboembolic prophylaxis following elective total hip arthroplasty. J Bone Joint Surg Am. 2000:929-938.

30. Hull RD, Pineo GF, Francis C, et al. Low-molecular-weight heparin prophylaxis using dalteparin in close proximity to surgery vs warfarin in hip arthroplasty patients: a double-blind, randomized comparison. The North American Fragmin Trial Investigators. Arch Intern Med. 2000;160(14):2199-2207.

31. Turpie AGG, Bauer KA, Eriksson BI, Lassen MR. Fondaparinux vs enoxaparin for the prevention of venous thromboembolism in major orthopedic surgery: a meta-analysis of 4 randomized double-blind studies. Arch Intern Med. 2002;162(12196081):1833-1840.
32. Howard AW, Aaron SD. Low molecular weight heparin decreases proximal and distal deep venous thrombosis following total knee arthroplasty. A meta-analysis of randomized trials. Thromb Haemost. 1998;79(5):902-906.

33. Bauer KA, Eriksson BI, Lassen MR, Turpie AG. Fondaparinux compared with enoxaparin for the prevention of venous thromboembolism after elective major knee surgery. $N$ Engl J Med. 2001;345(18): 1305-1310.

34. Lassen MR, Raskob GE, Gallus A, Pineo G, Chen D, Portman RJ. Apixaban or enoxaparin for thromboprophylaxis after knee replacement. N Engl J Med. August 6, 2009;361(6):594-604.

35. Lassen MR, Raskob GE, Gallus A, Pineo G, Chen D, Hornick P. Apixaban versus enoxaparin for thromboprophylaxis after knee replacement (ADVANCE-2): a randomised double-blind trial. Lancet 2010;375(9717):807-815.

36. Shorr AF, Nutescu EA, Farrelly E, Horblyuk R, Happe LE, Franklin M. Postdischarge oral versus injectable anticoagulation following major orthopedic surgery. Ann Pharmacother. 2008;42(9):1222-1228.

37. Dahl OE, Quinlan DJ, Bergqvist D, Eikelboom JW. A critical appraisal of bleeding events reported in venous thromboembolism prevention trials of patients undergoing hip and knee arthroplasty. J Thromb Haemost. 2010;8(9):1966-1975.

38. Tugwell P, Boers M, Brooks P, Simon L, Strand V, Idzerda L. OMERACT: an international initiative to improve outcome measurement in rheumatology. Trials. 2007;8:38.
Orthopedic Research and Reviews

\section{Publish your work in this journal}

Orthopedic Research and Reviews is an international, peer-reviewed, open access journal focusing on the patho-physiology of the musculoskeletal system, trauma, surgery and other corrective interventions to restore mobility and function. Advances in new technologies, materials, techniques and pharmacological agents are particularly welcome. The journal welcomes

\section{Dovepress}

original research, clinical studies, reviews \& evaluations, expert opinion and commentary, case reports and extended reports. The manuscript management system is completely online and includes a very quick and fair peer-review system, which is all easy to use. Visit http://www.dovepress. com/testimonials.php to read real quotes from published authors. 